Article

\title{
Poor Dietary Quality Is Associated with Low Adherence to Gestational Weight Gain Recommendations among Women in Sweden
}

\author{
Hanna Augustin * , Anna Winkvist $[$ and Linnea Bärebring \\ Department of Internal Medicine and Clinical Nutrition, Institute of Medicine, Sahlgrenska Academy, University \\ of Gothenburg, 40530 Gothenburg, Sweden; anna.winkvist@nutrition.gu.se (A.W.); linnea.barebring@gu.se (L.B.) \\ * Correspondence: hanna.augustin@gu.se; Tel.: +46-31-7863789
}

Received: 25 November 2019; Accepted: 20 January 2020; Published: 25 January 2020

check for updates

\begin{abstract}
Appropriate gestational weight gain (GWG) is important for fetal development and maternal health, but it is unclear what dietary factors predict GWG. The aim of this study was to investigate the association between dietary quality during pregnancy and GWG. In total, 1113 pregnant women were recruited when registering for antenatal care. GWG was defined according to the Institute of Medicine (IOM) guidelines. GWG was calculated as measured body weight at registration for antenatal care, to gestational week $37 \pm 2$. Dietary intake was assessed using a food frequency questionnaire (FFQ) administered in gestational week $>31$. In total, $40 \%$ gained within the IOM GWG recommendations, $25 \%$ had insufficient GWG and 35\% excessive GWG. Women with a poor or fair quality diet gained approximately $2 \mathrm{~kg}$ more than women with a high-quality diet. Poor dietary quality was also associated with higher odds of excessive GWG, due to fat quality and intake of discretionary foods. In conclusion, poor quality dietary intake is associated with lower adherence to the guidelines on weight gain in pregnancy. A diet characterised by high-quality fat intake, low consumption of discretionary foods and high nutrient intake may promote healthy weight gain and prevent excessive GWG.
\end{abstract}

Keywords: gestational weight gain; pregnancy complications; nutrition; dietary intake

\section{Introduction}

Adequate gestational weight gain (GWG) is important for both fetal development and maternal health [1]. On the one hand, low GWG increases risk of infant small for gestational age (SGA) [2-4] and preterm delivery $[1,5]$. On the other hand, high GWG increases risk of infant large for gestational age (LGA) [2-4], preterm delivery [3], caesarean section (C-section) [5], maternal hypertension [1] and postpartum weight retention [2,6]. Both high and low GWG are associated with higher offspring fat mass during childhood [7]. In addition, high maternal GWG is associated with increased risk of offspring overweight and obesity [8].

GWG is regarded a greater contributor to adverse pregnancy outcomes than maternal body mass index (BMI) [3]. The risks associated with inadequate or excessive GWG are however modified by maternal pre-pregnancy BMI [9]. Therefore, the American Institute of Medicine (IOM) bases their recommendations on appropriate GWG on pre-pregnancy BMI. According to the IOM guidelines, recommended GWG is $12.5-18 \mathrm{~kg}$ for underweight women, $11.5-16 \mathrm{~kg}$ for normal weight women, $7-11.5 \mathrm{~kg}$ for overweight women and 5-9 kg for obese women [1]. Weight gain below or above the recommended range is considered inadequate or excessive.

Excessive GWG is increasingly common worldwide [1]. In Sweden, 36\% of normal weight and $76 \%$ of overweight or obese women gain excessively during pregnancy [10]. This is of increasing 
concern since BMI in early pregnancy is increasing. From 1992 to 2016, mean early pregnancy BMI increased from 23.4 to $25 \mathrm{~kg} / \mathrm{m}^{2}$ and the rate of overweight or obesity from $25 \%$ to $40 \%$ [11]. During the same time period, the rate of induced labour, caesarean section, and stillbirth increased, while the rate of infants with high birth weight $(\geq 4500 \mathrm{~g})$ and preterm delivery remained constant [11].

Dietary intervention during pregnancy may reduce the risk of excessive GWG by approximately $20 \%$ [12]. Data from Norway show that higher adherence to the New Nordic Diet, characterised by a high intake of fruit, vegetables, whole grains, potatoes, fish, game, milk and drinking water, is associated with optimal GWG and fetal growth [13]. While no association was seen between overall dietary quality and GWG in a US population [14], intake of specific foods (meat, dairy, fruit, vegetables, nuts) were associated with lower risk of excessive GWG [15]. Little is known about the effects of overall dietary quality on GWG. Additionally, very few data are available on nutritional intake among pregnant women in Sweden. Previous studies have found that reported dietary intake among pregnant Swedish women is of poor quality [16], with a low intake of many nutrients [17]. Neither of the previous studies have investigated associations between diet and GWG. We have previously shown, in a study of well-educated women, that higher intake of caloric beverages, snacks, fish and bread during pregnancy is associated with higher GWG [18]. To our knowledge, there are no population-based data published on dietary quality and GWG in Sweden. The aim of this study is therefore to investigate the associations between dietary intake quality and GWG in a population-based Swedish cohort. We hypothesise that poor dietary quality is associated with lower adherence to the IOM guidelines for GWG.

\section{Materials and Methods}

\subsection{Recruitment and Inclusion}

Pregnant women from the population-based GraviD cohort in the south-west of Sweden were included in this study. The cohort has been described in detail elsewhere [19]. In brief, 2125 women were included in the cohort when registering for antenatal care during autumn 2013 and spring 2014. In Sweden, antenatal care is free of charge to all pregnant women. All data collection was performed during routine visits throughout pregnancy. In the current analyses, inclusion criteria were singleton pregnancy and a provided food frequency questionnaire (FFQ). Women were excluded if they registered for antenatal care in gestational week $>14$, miscarried, delivered before gestational week 34 , had missing data on pregnancy weight $(N=16)$, or implausible energy intake $(<500 \mathrm{kcal} /$ day, $N=7)$. A total of 1113 women were included in the analyses. All participants provided signed informed consent and all procedures were conducted in accordance with the Declaration of Helsinki.

\subsection{Data Collection and Assessment of Dietary Intake}

Maternal body weight was retrieved from medical records. Early pregnancy BMI was defined by the first measured body weight and classified as underweight $\left(<18.5 \mathrm{~kg} / \mathrm{m}^{2}\right)$, normal weight $\left(18.5-24.9 \mathrm{~kg} / \mathrm{m}^{2}\right)$, overweight $\left(25-29.9 \mathrm{~kg} / \mathrm{m}^{2}\right)$, and obese $\left(>30 \mathrm{~kg} / \mathrm{m}^{2}\right)$. GWG was calculated as body weight in gestational week $37 \pm 2$ weeks minus weight in gestational week $\leq 14$. Those with complete weight data, or sufficient data to enable imputation, were included in the current analyses. If weight in gestational week 37 was missing, data were considered sufficient for imputation if there was a weight in gestational week $\leq 14$, and in either gestational week 25 or 32 . Imputation of total weight gain was performed using the mean GWG among women with the same early pregnancy BMI and the same GWG in week 25 or 32 . This enabled the inclusion of an additional 58 women.

Data on obstetric outcomes were retrieved from medical records. The definitions of SGA and LGA were either weight or length at birth below or above $2 \mathrm{SD}$ of the gender-specific population mean. Delivery by emergency C-section was defined as C-section after the onset of labor.

In the last trimester of pregnancy, all women were asked to answer an online semi-quantitative FFQ $[20,21]$ that provided intake data on food levels, as well as macro- and micronutrient levels. The questionnaire has been validated among non-pregnant adults for macro- and micronutrients 
against 7-day food records and doubly-labelled water. In brief, reproducibility of nutritional intake was fair to high at $r=0.43-0.92$ and validity was fair for intakes of most nutrients [20,21]. The FFQ took approximately $20 \mathrm{~min}$ to complete and specified dietary habits during the previous two months, thus reflecting intake in the second to early third trimester. A dietary quality index developed by the National Food Agency was used to determine dietary quality [22]. The index is designed to capture dietary quality (fibre, fat and discretionary foods) and compliance with dietary recommendations (intakes of fruit, vegetables, fish and whole grain bread). It scores intake of fruit and vegetables, whole grain bread, fish and shellfish, discretionary foods (sweets, cakes, soft drinks and French fries), margarine and butter, cheese and sausage, with a total min-max score of $0-12$ points. Dietary quality was defined as poor ( $\leq 4$ points), fair (5-8 points) or high ( $\geq 9$ points). Positive contributors to the index are frequent intakes of fruit, vegetables, whole grain bread and fish. Negative contributors are frequent intakes of cheese, sausage and discretionary foods. Use of low fat margarine $(\leq 40 \%)$ contributes positively while the use of high fat margarine or butter $(\geq 60 \%)$ contributes negatively.

\subsection{Statistical Analysis}

Comparisons of nutritional intake depending on dietary quality (poor, fair and high) were performed using the Kruskal Wallis test. Associations between GWG and gestational outcomes SGA, LGA and emergency C-section were studied using logistic regression analysis. Associations between dietary quality and GWG were studied using linear and logistic regression analysis. All regression analyses were adjusted for gestational age at first visit (at first weighing), gestational age at delivery, maternal age, early pregnancy BMI, nulliparity, early pregnancy tobacco use, education level and pre-existing medical conditions (defined as renal, cardiovascular (including chronic hypertension), asthma or autoimmune medical conditions (diabetes mellitus, systemic lupus erythematosus or rheumatoid arthritis)). All analyses were conducted using SPSS Statistics version 25 (IBM Corp., Armonk, NY, USA). A total of 1113 women from the GraviD cohort were eligible for inclusion in this paper. Power calculations showed that this sample size would yield $77 \%$ power (alpha 0.05 ) to detect a $23 \%$ increased risk of excessive GWG among those with poor diet [23], (31\% vs. 38\% excessive GWG among those with high and poor quality diet, respectively). We assumed an overall $60 \%$ prevalence of poor dietary quality [16].

\section{Results}

\subsection{Gestational Weight Gain}

The characteristics of the women can be seen in Table 1. Mean (SD) GWG from registration for antenatal care to gestational week $37 \pm 2$ weeks was 13.6 (4.8) $\mathrm{kg}$. In total, $40 \%$ gained within the IOM recommendations, $25 \%$ below and 35\% gained more than recommended (Table 2). Mean GWG in $\mathrm{kg}$ for women with early pregnancy underweight, normal weight, overweight and obesity was 12.7 (4.9), 13.9 (4.4), 13.7 (5.3) and $11.7(6.0)$, respectively.

Table 1. Characteristics of the 1113 pregnant women from the GraviD cohort.

\begin{tabular}{lcc}
\hline Continous Variables & Mean & SD \\
\hline Gestational age at first visit (days) & 57.9 & 13.0 \\
Gestational age at delivery (days) & 281.3 & 8.9 \\
Gestational weight gain (kg) & 13.6 & 4.9 \\
Maternal age (years) & 31.9 & 4.6 \\
BMI at first visit (days) & 24.1 & 4.0 \\
Dietary quality index score (0-12 points) & 4.8 & 1.9 \\
\hline
\end{tabular}


Table 1. Cont.

\begin{tabular}{|c|c|c|}
\hline Continous Variables & Mean & SD \\
\hline Categorical variables & $\%$ & $N$ \\
\hline \multicolumn{3}{|l|}{ Parity } \\
\hline 0 children & 42.5 & 473 \\
\hline 1 child & 42.4 & 472 \\
\hline 2 children & 12.2 & 136 \\
\hline$\geq 3$ children & 2.9 & 32 \\
\hline \multicolumn{3}{|l|}{ Marital status } \\
\hline Cohabitating with father & 96.4 & 1068 \\
\hline Single & 1.4 & 16 \\
\hline Other ${ }^{1}$ & 2.2 & 24 \\
\hline \multicolumn{3}{|l|}{ Birth place } \\
\hline North Europe & 86.2 & 959 \\
\hline Continental Europe & 5.1 & 57 \\
\hline Asia & 5.7 & 63 \\
\hline Africa & 1.4 & 16 \\
\hline America & 1.6 & 18 \\
\hline \multicolumn{3}{|l|}{ Education } \\
\hline Primary level & 1.5 & 17 \\
\hline Secondary level & 29.8 & 331 \\
\hline University level & 68.7 & 764 \\
\hline \multicolumn{3}{|l|}{ Tobacco use in early pregnancy } \\
\hline Yes & 3.9 & 43 \\
\hline No & 96.1 & 1070 \\
\hline \multicolumn{3}{|l|}{ Alcohol use in early pregnancy } \\
\hline None & 98.3 & 1043 \\
\hline$\leq 1$ time/week & 1.7 & 18 \\
\hline \multicolumn{3}{|c|}{ Supplement use in third trimester } \\
\hline Any & 62.6 & 684 \\
\hline None & 37.4 & 409 \\
\hline
\end{tabular}

${ }^{1}$ As stated in the medical records, and includes women who are living separate from the father, or who are in a same-sex relationship.

Table 2. Gestational weight gain according to the Institute of Medicines guidelines (1), among all women and per first trimester BMI category.

\begin{tabular}{|c|c|c|c|c|c|}
\hline $\begin{array}{l}\text { Gestational } \\
\text { Weight Gain }\end{array}$ & $\begin{array}{c}\text { All } \\
N(\%)\end{array}$ & $\begin{array}{c}\text { Underweight } \\
\text { (BMI < 18.5) } \\
N(\%)\end{array}$ & $\begin{array}{c}\text { Normal Weight } \\
\text { (BMI 18.5-25) } \\
\text { N (\%) }\end{array}$ & $\begin{array}{c}\text { Overweight } \\
\text { (BMI 25-30) } \\
N(\%)\end{array}$ & $\begin{array}{c}\text { Obese } \\
(\mathrm{BMI}>30) \\
N(\%)\end{array}$ \\
\hline Insufficient & $275(24.7)$ & $12(46.2)^{a}$ & $228(30.9)^{a}$ & $24(9.4)^{b}$ & $11(11.7)^{b}$ \\
\hline Adequate & 449 (40.3) & $11(42.3)^{a, b}$ & $344(46.7)^{b}$ & $71(27.7)^{\mathrm{a}}$ & $23(24.5)^{\mathrm{a}}$ \\
\hline Excessive & $389(35.0)$ & $3(11.5)^{a}$ & $165(22.4)^{\mathrm{a}}$ & $161(62.9)^{b}$ & $60(63.8)^{b}$ \\
\hline Total & $1113(100)$ & $26(100)$ & 737 (100) & $256(100)$ & $94(100)$ \\
\hline
\end{tabular}

$\mathrm{a}, \mathrm{b}$ denotes non-significant proportions $(p>0.05)$ in gestational weight gain among the women grouped by first trimester body mass index (BMI).

Women with insufficient GWG had almost three-fold higher OR of having a child born SGA than women who gained within the recommendations ( $\mathrm{OR}=2.94, p=0.004$; Table 3). Similarly, women with excessive GWG had a nearly two-fold higher OR of LGA than those with adequate GWG, though this was not significant. Additionally, excessive GWG was associated with a nearly two-fold higher OR of delivery by emergency C-section, compared to adequate $\mathrm{GWG}(\mathrm{OR}=1.91, p=0.02)$. 
Table 3. Associations between pregnancy outcomes and gestational weight gain, classified according to compliance with the gestational weight gain recommendations from the Institute of Medicine [1], among women in the GraviD cohort.

\begin{tabular}{cccccccc}
\hline \multirow{2}{*}{ Gestational Weight Gain } & \multicolumn{2}{c}{ SGA } & \multicolumn{2}{c}{ LGA } & \multicolumn{3}{c}{ ASEC } \\
\cline { 2 - 8 } & OR $^{\mathbf{1}}$ & $\boldsymbol{p}$ & OR $^{\mathbf{1}}$ & $\boldsymbol{p}$ & OR $^{\mathbf{1}}$ & $\boldsymbol{p}$ \\
\hline Adequate (ref) & 1.0 & & 1.0 & & 1.0 & \\
Insufficient & 2.94 & 0.004 & 0.17 & 0.090 & 1.33 & 0.386 \\
Excessive & 0.82 & 0.645 & 1.67 & 0.240 & 1.91 & 0.023
\end{tabular}

SGA, small for gestational age; LGA, large for gestational age; ASEC, emergency caesarean section. ${ }^{1}$ Logistic regression model adjusted for gestational age at inclusion, gestational age at delivery, maternal age, early pregnancy BMI, parity, pre-existing maternal illness, tobacco use in early pregnancy and education level.

\subsection{Dietary Quality and Nutritional Intake}

Most of the women (54\%) had fair dietary quality, $44 \%$ a poor quality diet, while only $3 \%$ had a high-quality diet. The nutritional intake of the women met the recommended daily intake for most nutrients (Table 4). However, only 10\%-50\% complied with the recommended daily intake of fiber, vitamin $\mathrm{A}$, thiamine, vitamin $\mathrm{E}$ and potassium. The proportion who reached the average requirement of vitamin $\mathrm{A}$, thiamine and vitamin $\mathrm{E}$ was $76 \%, 82 \%$ and $88 \%$, respectively. Furthermore, $\leq 10 \%$ of the women complied with the recommended intake of saturated fatty acids, folate, vitamin D and selenium. The proportion who reached the average requirement of folate, vitamin $\mathrm{D}$ and selenium was $83 \%, 20 \%$ and $73 \%$, respectively.

A higher dietary quality was related to higher intake of fibre $(p<0.001)$ and protein $(p<0.001)$, lower intake of total fat $(p<0.001)$ and saturated fat $(p<0.001)$ and higher intake of mono- $(p=0.020)$ and polyunsaturated fat $(p<0.001)$. Further, for most micronutrients, mean intake increased with increasing dietary quality (Table 4 ).

Linear regression analysis showed that, compared to women with a high-quality diet, those with poor $(\mathrm{B}=2.286, p=0.013)$ or fair $(\mathrm{B}=1.951, p=0.031)$ dietary quality had a higher $\mathrm{GWG}$ corresponding to approximately $2 \mathrm{~kg}$. Lower GWG was mainly associated with higher quality fat intake $(B=-0.313, p$ $=0.007)$, but not with intake of fibre $(B=0.110, p=0.418)$ or discretionary foods $(B=-0.241, p=0.267)$. Logistic regression analysis showed that poor and fair dietary quality were associated with higher odds of excessive GWG, compared to a high-quality diet (Table 5). This association seemed to depend mainly on higher-quality fat intake and a lower intake of discretionary foods.

Table 4. Nutritional intake in pregnancy among the women in the GraviD cohort, assessed by a food frequency questionnaire.

\begin{tabular}{|c|c|c|c|c|c|c|c|}
\hline \multirow[t]{2}{*}{ Nutrient } & \multirow[t]{2}{*}{$\mathbf{R I}^{1}$} & \multirow[t]{2}{*}{$\mathrm{AR}^{2}$} & \multirow{2}{*}{$\begin{array}{c}\text { All } \\
(N=1113)\end{array}$} & \multirow{2}{*}{ 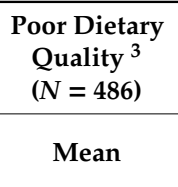 } & \multirow{2}{*}{$\begin{array}{c}\begin{array}{c}\text { Fair Dietary } \\
\text { Quality }^{3} \\
(N=597)\end{array} \\
\text { Mean }\end{array}$} & \multirow{2}{*}{$\begin{array}{c}\begin{array}{c}\text { High Dietary } \\
\text { Quality }{ }^{3} \\
(N=30)\end{array} \\
\text { Mean }\end{array}$} & \multirow[t]{2}{*}{$p^{5}$} \\
\hline & & & & & & & \\
\hline Energy (kJ) & - & - & 7982 (3294) & 7663 (3226) & 8239 (3347) & 8036 (2944) & 0.001 \\
\hline Energy (kcal) & - & - & 1908 (787) & $1831(771)$ & $1969(800)$ & $1921(704)$ & 0.001 \\
\hline Carbohydrate E\% & $45-60$ & - & $48(6)$ & $48(6)$ & $48(5)$ & $48(7)$ & 0.792 \\
\hline Fiber g/MJ & 3 & - & $3(1)$ & $2(1)$ & $3(1)$ & $4(1)$ & $<0.001$ \\
\hline Protein E\% & $10-20$ & - & $16(3)$ & $16(3)$ & 17 (3) & $18(3)$ & $<0.001$ \\
\hline Total fat E\% & $25-40$ & - & $33(5)$ & $34(5)$ & $32(5)$ & $31(6)$ & $<0.001$ \\
\hline Saturated fat E\% & $<10$ & - & $14(3)$ & $15(3)$ & $13(3)$ & $11(2)$ & $<0.001$ \\
\hline MUFA E\% & $10-20$ & - & $11(2)$ & $12(2)$ & $12(2)$ & $11(2)$ & 0.020 \\
\hline PUFA E\% & $5-10$ & - & $5(2)$ & $5(2)$ & $5(2)$ & $6(2)$ & $<0.001$ \\
\hline Vitamin A (RE) & 800 & 500 & 752 (355) & 655 (314) & $823(366)$ & 903 (391) & $<0.001$ \\
\hline Thiamine (mg) & 1.5 & 0.9 & $1.4(0.6)$ & $1.3(0.6)$ & $1.5(0.7)$ & $1.7(0.6)$ & $<0.001$ \\
\hline Niacin (NE) & 17 & 12 & $31(11)$ & $28(10)$ & $32(12)$ & $35(11)$ & $<0.001$ \\
\hline
\end{tabular}


Table 4. Cont.

\begin{tabular}{|c|c|c|c|c|c|c|c|}
\hline \multirow[t]{2}{*}{ Nutrient } & \multirow[t]{2}{*}{ RI $^{1}$} & \multirow[t]{2}{*}{$\mathrm{AR}^{2}$} & $\begin{array}{c}\text { All } \\
(N=1113)\end{array}$ & $\begin{array}{c}\text { Poor Dietary } \\
\text { Quality }^{3} \\
(N=486)\end{array}$ & $\begin{array}{c}\text { Fair Dietary } \\
\text { Quality }^{3} \\
(N=597)\end{array}$ & $\begin{array}{l}\text { High Dietary } \\
\text { Quality } \\
\\
(N=30)\end{array}$ & \multirow[t]{2}{*}{$p^{5}$} \\
\hline & & & $\begin{array}{c}\text { Mean } \\
\text { (SD) }\end{array}$ & Mean & Mean & Mean & \\
\hline Riboflavin (mg) & 1.6 & 1.1 & $2.0(0.8)$ & $1.9(0.8)$ & $2.0(0.8)$ & $2.2(0.8)$ & 0.001 \\
\hline Vitamin B6 (mg) & 1.4 & 1.0 & $2.0(0.8)$ & $1.7(0.7)$ & $2.1(0.8)$ & $2.4(0.9)$ & $<0.001$ \\
\hline Folate $(\mu \mathrm{g})$ & 500 & 200 & 321 (133) & $272(115)$ & $355(131)$ & $430(156)$ & $<0.001$ \\
\hline Vitamin B12 $(\mu \mathrm{g})$ & 2.0 & 1.4 & $5(2)$ & $5(2)$ & $5(2)$ & $6(3)$ & $<0.001$ \\
\hline Vitamin C (mg) & 85 & 50 & $125(68)$ & $103(61)$ & $142(68)$ & $168(56)$ & $<0.001$ \\
\hline Vitamin D $(\mu \mathrm{g})$ & 10 & 7.5 & $6(3)$ & $5(2)$ & $6(3)$ & $8(4)$ & $<0.001$ \\
\hline Vitamin E (mg) & 10 & 5 & $9(4)$ & $8(4)$ & $10(4)$ & $11(4)$ & $<0.001$ \\
\hline Calcium (mg) & 900 & 500 & $1064(473)$ & $1050(490)$ & 1079 (465) & $976(327)$ & 0.351 \\
\hline Phosphorus (mg) & 700 & 450 & $1420(543)$ & $1320(522)$ & $1496(550)$ & $1542(472)$ & $<0.001$ \\
\hline Potassium (g) & 3100 & - & 3143 (1110) & 2814 (1036) & 3386 (1096) & 3610 (1157) & $<0.001$ \\
\hline Magnesium (mg) & 280 & - & 349 (139) & $306(125)$ & 381 (139) & 417 (139) & $<0.001$ \\
\hline Iron (mg) & -4 & -4 & $12(5)$ & $10(5)$ & $13(5)$ & $14(5)$ & $<0.001$ \\
\hline Zinc (mg) & 9 & 5 & $10(4)$ & $10(4)$ & $11(4)$ & $11(3)$ & $<0.001$ \\
\hline Selenium ( $\mu \mathrm{g})$ & 60 & 30 & $40(16)$ & $36(14)$ & $44(16)$ & $50(15)$ & $<0.001$ \\
\hline
\end{tabular}

RI, recommended daily intake; $\mathrm{AR}$, average requirement; $\mathrm{E} \%$, energy percent; MUFA, monounsaturated fatty acids; PUFA, polyunsaturated fatty acids. ${ }^{1}$ RI for pregnant women in the 2011-2012 Nordic Nutrition Recommendations. 2 AR for women in the 2011-2012 Nordic Nutrition Recommendations. ${ }^{3}$ Dietary quality assessed by an index (score 0-12) designed to indicate intake of fibre, fat and discretionary food, where $\leq 4$ points equals poor dietary quality, 5-8 points fair dietary quality and $\geq 9$ points high dietary quality [22]. ${ }^{4}$ Pregnancy requires $500 \mathrm{mg}$ of stored iron. Supplementation is necessary for some women when dietary intake is insufficient to meet the extra needs.

${ }^{5}$ Differences between groups were assessed by the Kruskal Wallis test.

Table 5. Associations between mid-pregnancy dietary quality and adherence to the Institute of Medicine guidelines for gestational weight gain (GWG) [1] among women in the GraviD cohort.

\begin{tabular}{lcccccc}
\hline & \multicolumn{2}{c}{ Insufficient GWG } & \multicolumn{2}{c}{ Adequate GWG } & \multicolumn{2}{c}{ Excessive GWG } \\
\cline { 2 - 7 } & OR $^{\mathbf{1}}$ & $\boldsymbol{p}$ & OR $^{\mathbf{1}}$ & $\boldsymbol{p}$ & OR $^{\mathbf{1}}$ & $\boldsymbol{p}$ \\
\hline Dietary quality $^{\mathbf{2}}$ & & & & & & \\
$\quad$ High quality diet (ref) & 1.0 & & 1.0 & & 1.0 & \\
$\quad$ Fair quality diet & 0.580 & 0.168 & 0.804 & 0.567 & 3.291 & 0.038 \\
$\quad$ Poor quality diet & 0.400 & 0.023 & 0.831 & 0.630 & 4.351 & 0.010 \\
\hline$\quad$ Components of index & & & & & & \\
$\quad$ Fibre intake score (0-4 points) & 1.043 & 0.536 & 0.961 & 0.499 & 1.012 & 0.849 \\
$\quad$ Fat intake score (0-6 points) & 1.225 & $<0.001$ & 0.961 & 0.419 & 0.876 & 0.014 \\
$\quad$ Discretionary food intake score (0-2 points) & 1.050 & 0.645 & 1.126 & 0.202 & 0.818 & 0.053 \\
\hline
\end{tabular}

\footnotetext{
${ }^{1}$ Logistic regression models were adjusted for gestational age at registration in the first trimester, total gestational duration, maternal age, BMI in the first trimester, nulliparity, preexisting medical disorders, tobacco use in the first trimester and education level. ${ }^{2}$ Dietary quality assessed by an index (score $0-12$ ) designed to indicate intake of fibre, fat and discretionary food, where $\leq 4$ points equals poor dietary quality, 5-8 points fair dietary quality and $\geq 9$ points high dietary quality [22]. ${ }^{3}$ Higher scores indicate higher dietary quality.
}

\section{Discussion}

This prospective cohort study showed that $40 \%$ of the 1113 pregnant women gained within the IOM recommendations for GWG, $25 \%$ gained insufficiently and $35 \%$ excessively. Only $3 \%$ of the women had a high-quality diet. A poor or fair quality diet was associated with three to four times higher odds of excessive GWG, compared to a high-quality diet. Excessive GWG was associated with poorer fat quality and higher intake of discretionary foods.

Only $3 \%$ of the women in the current study were classified as having a high-quality diet. Median dietary quality score was 5 , which is comparable to findings by Wennberg et al. who found a median score of 4 among pregnant Swedish women using the same index [16]. This previous smaller study assessed nutritional intake in the first trimester of pregnancy. It is unclear if the slightly higher median dietary quality in our study can be explained by chance, methodological differences or by better dietary habits later in pregnancy, when early pregnancy nausea and vomiting have subsided. The latter 
explanation is supported by previous research suggesting that these symptoms are associated with a higher intake of soft drinks and a deterioration in dietary quality [24,25]. The nutrient intake in the current study is similar to the intake in a recent study using the same FFQ among pregnant women in the north of Sweden [17].

The dietary quality assessed by the National Food Agency's index seemed to be reflected in most nutrients, as nutritional intake was higher with increasing dietary quality. The recommended daily intake for most nutrients was met but only $\leq 10 \%$ of the women complied with the recommended intake of saturated fatty acids, folate, vitamin D and selenium. We have previously shown that almost $80 \%$ of women take nutritional supplements during pregnancy [26] and that many take the recommended folate in a multivitamin supplement. The contribution of supplements to overall micronutrient intake can therefore be substantial. Since the dietary intake of several micronutrients was low, the use of nutritional supplements during pregnancy may be warranted. However, overall dietary quality should also be improved as very few women were characterized as having a high-quality diet.

Women with a poor or fair quality diet had a significantly higher GWG than women with a high-quality diet, and they gained approximately $2 \mathrm{~kg}$ more. Further, poor dietary quality was associated with higher odds of excessive GWG, due to fat quality and intake of discretionary food. These findings are in line with results from Norway and the US, indicating that food choices are related to GWG $[13,15]$. Similar to previous findings $[27,28]$, insufficient GWG in our study was most common among underweight women while excessive GWG was most common among women with overweight or obesity.

Limitations of this work include self-reported data on dietary intake, and that GWG was based on weights measured in early and late pregnancy, and weight changes before or after these time points cannot be ruled out. However, first trimester weight correlates well with self-reported pre-pregnancy weight, though pre-pregnancy weight is lower [29]. Consequently, early pregnancy weight is likely valid for ranking women according to their GWG. Still, an underestimation of the total GWG is probable. Furthermore, body weight was not measured in a standardised way and inconsistencies in clothing and time of day are likely. An additional limitation is the constant challenge in assessing dietary micronutrient intake with precision [20], and these results should be interpreted with some caution. The FFQ has only been validated in a non-pregnant population and its validity during pregnancy is uncertain. We have previously shown that the FFQ is valid for the estimation of dietary vitamin D intake among pregnant women [30], but the validation of other nutrients and dietary quality is warranted. The FFQ was administered in gestational week $>31$ and reflected dietary intake during the previous two months. Dietary intake in the first half of pregnancy, or after gestational week 31 , is likely also important for GWG. Other limitations are missing information on factors that could impact GWG such as hyperemesis gravidarum, physical activity, dieting, thyroid hormone function and inter-pregnancy interval for parous women. Strengths include measured rather than self-reported weight and the relativity large cohort size. The GraviD cohort is population-based and while the FFQ was only available in Swedish, the FFQ respondents were similar to the overall cohort except for birth place; a slightly higher proportion was born in Sweden among the FFQ respondents (85\%) than in the overall cohort $(74 \%)$.

\section{Conclusions}

In conclusion, poor quality dietary intake is associated with lower adherence to the guidelines on weight gain in pregnancy. A diet characterised by high-quality fat intake, low consumption of discretionary foods and high nutrient intake may promote healthy weight gain and prevent excessive GWG.

Author Contributions: Conceptualization, L.B., A.W. and H.A.; Methodology, A.W., L.B. and H.A.; Formal analysis, L.B.; Investigation, H.A. and L.B.; Resources, H.A. and A.W.; Data curation, L.B.; Writing-Original draft preparation, L.B.; Writing-Review and editing, L.B., H.A., A.W.; Project administration, H.A., L.B.; Funding acquisition, H.A. All authors have read and agreed to the published version of the manuscript. 
Funding: This research was funded by The Swedish Research Council for Health, Working Life and Welfare, grant number 2018-00441 and Regional Research and Development Grant (VGFOUREG-388201 and VGFOUREG-229331).

Acknowledgments: The authors would like to thank all the women who participated in the study and the midwives and nurses who participated in recruitment and data collection.

Conflicts of Interest: The authors declare no conflict of interest.

\section{References}

1. Weight Gain during Pregnancy: Reexamining the Guidelines; Rasmussen, K.M., Yaktine, A.L., Eds.; National Academy of Sciences: Washington, DC, USA, 2009.

2. Siega-Riz, A.M.; Viswanathan, M.; Moos, M.-K.; Deierlein, A.; Mumford, S.; Knaack, J.; Thieda, P.; Lux, L.J.; Lohr, K.N. A systematic review of outcomes of maternal weight gain according to the Institute of Medicine recommendations: Birthweight, fetal growth, and postpartum weight retention. Am. J. Obstet. Gynecol. 2009, 201, 339.e1-339.e14. [CrossRef]

3. Dzakpasu, S.; Fahey, J.; Kirby, R.S.; Tough, S.C.; Chalmers, B.; I Heaman, M.; Bartholomew, S.; Biringer, A.; Darling, E.K.; Lee, L.S.; et al. Contribution of prepregnancy body mass index and gestational weight gain to adverse neonatal outcomes: Population attributable fractions for Canada. BMC Pregnancy Childbirth 2015, 15, 21. [CrossRef]

4. Santos, S.; Voerman, E.; Amiano, P.; Barros, H.; Beilin, L.J.; Bergström, A.; Charles, M.-A.; Chatzi, L.; Chevrier, C.; Chrousos, G.P.; et al. Impact of maternal body mass index and gestational weight gain on pregnancy complications: An individual participant data meta-analysis of European, North American, and Australian cohorts. BJOG Int. J. Obstet. Gynaecol. 2019, 126, 984-995. [CrossRef]

5. Koh, H.; Ee, T.X.; Malhotra, R.; Allen, J.C.; Tan, T.C.; Østbye, T. Predictors and adverse outcomes of inadequate or excessive gestational weight gain in an Asian population. J. Obstet. Gynaecol. Res. 2013, 39, 905-913. [CrossRef]

6. Amorim, A.R.; Rossner, S.; Neovius, M.; Lourenço, P.M.; Linné, Y. Does Excess Pregnancy Weight Gain Constitute a Major Risk for Increasing Long-term BMI?*. Obesity 2007, 15, 1278-1286. [CrossRef] [PubMed]

7. Crozier, S.R.; Inskip, H.M.; Godfrey, K.M.; Cooper, C.; Harvey, N.C.; Cole, Z.A.; Robinson, S.M. Weight gain in pregnancy and childhood body composition: Findings from the Southampton Women's Survey. Am. J. Clin. Nutr. 2010, 91, 1745-1751. [CrossRef] [PubMed]

8. Voerman, E.; Santos, S.; Patro Golab, B.; Amiano, P.; Ballester, F.; Barros, H.; Bergström, A.; Charles, M.A.; Chatzi, L.; Chevrier, C.; et al. Maternal body mass index, gestational weight gain, and the risk of overweight and obesity across childhood: An individual participant data meta-analysis. PLoS Med. 2019, 16, e1002744. [CrossRef] [PubMed]

9. Cedergren, M. Effects of gestational weight gain and body mass index on obstetric outcome in Sweden. Int. J. Gynecol. Obstet. 2006, 93, 269-274. [CrossRef] [PubMed]

10. Holowko, N.; Mishra, G.; Koupil, I. Social inequality in excessive gestational weight gain. Int. J. Obes. 2014, 38, 91-96. [CrossRef] [PubMed]

11. The National Board of Health and Welfare. Statistics on Pregnancies, Deliveries and Newborn Infants 2016. Available online: https://www.socialstyrelsen.se/publikationer2018/2018-1-7 (accessed on 21 September 2018).

12. Muktabhant, B.; Lawrie, T.A.; Lumbiganon, P.; Laopaiboon, M. Diet or exercise, or both, for preventing excessive weight gain in pregnancy. Cochrane Database Syst. Rev. 2015, 6, 15. [CrossRef] [PubMed]

13. Hillesund, E.R.; Bere, E.; Haugen, M.; Øverby, N.C. Development of a New Nordic Diet score and its association with gestational weight gain and fetal growth-A study performed in the Norwegian Mother and Child Cohort Study (MoBa). Public Health Nutr. 2014, 17, 1909-1918. [CrossRef] [PubMed]

14. Shin, D.; Bianchi, L.; Chung, H.; Weatherspoon, L.; Song, W.O. Is gestational weight gain associated with diet quality during pregnancy? Matern. Child Health J. 2014, 18, 1433-1443. [CrossRef] [PubMed]

15. Shin, D.; Lee, K.W.; Song, W.O. Dietary Patterns during Pregnancy are Associated with Gestational Weight Gain. Matern. Child Heal. J. 2016, 20, 2527-2538. [CrossRef] [PubMed]

16. Wennberg, A.L.; Isaksson, U.; Sandström, H.; Lundqvist, A.; Hörnell, A.; Hamberg, K. Swedish women's food habits during pregnancy up to six months post-partum: A longitudinal study. Sex. Reprod. Healthc. 2016, 8, 31-36. [CrossRef] [PubMed] 
17. Stråvik, M.; Jonsson, K.; Hartvigsson, O.; Sandin, A.; Wold, A.E.; Sandberg, A.-S.; Barman, M. Food and Nutrient Intake during Pregnancy in Relation to Maternal Characteristics: Results from the NICE Birth Cohort in Northern Sweden. Nutrients 2019, 11, 1680. [CrossRef] [PubMed]

18. Bärebring, L.; Brembeck, P.; Löf, M.; Brekke, H.K.; Winkvist, A.; Augustin, H. Food intake and gestational weight gain in Swedish women. SpringerPlus 2016, 5, 377. [CrossRef]

19. Bärebring, L.; Schoenmakers, I.; Glantz, A.; Hulthén, L.; Jagner, Å.; Ellis, J.; Bärebring, M.; Bullarbo, M.; Augustin, H. Vitamin D Status during Pregnancy in a Multi-Ethnic Population-Representative Swedish Cohort. Nutrients 2016, 8, 655. [CrossRef]

20. Christensen, S.E.; Möller, E.; Bonn, S.E.; Ploner, A.; Bälter, O.; Lissner, L.; Bälter, K.; Brantsaeter, A.-L.; Barrat, E. Relative Validity of Micronutrient and Fiber Intake Assessed With Two New Interactive Meal- and Web-Based Food Frequency Questionnaires. J. Med. Internet Res. 2014, 16, e59. [CrossRef]

21. Christensen, S.E.; Möller, E.; Bonn, S.E.; Ploner, A.; Wright, A.; Sjölander, A.; Bälter, O.; Lissner, L.; Bälter, K.; De Vries, J. Two New Meal- and Web-Based Interactive Food Frequency Questionnaires: Validation of Energy and Macronutrient Intake. J. Med. Internet Res. 2013, 15, e109. [CrossRef]

22. Becker Wolf. Indikatorer för Bra Matvanor-Resultat Från Intervjuundersökningar 2008; National Food Agency: Uppsala, Sweden, 2009.

23. Hrolfsdottir, L.; Halldorsson, T.I.; Birgisdottir, B.E.; Hreidarsdottir, I.T.; Hardardottir, H.; Gunnarsdottir, I. Development of a dietary screening questionnaire to predict excessive weight gain in pregnancy. Matern. Child Nutr. 2019, 15, e12639. [CrossRef]

24. Chortatos, A.; Haugen, M.; Iversen, P.; Vikanes, Å.; Magnus, P.; Veierød, M.B. Nausea and vomiting in pregnancy: Associations with maternal gestational diet and lifestyle factors in the Norwegian Mother and Child Cohort Study. BJOG Int. J. Obstet. Gynaecol. 2013, 120, 1642-1653. [CrossRef] [PubMed]

25. Crozier, S.R.; Inskip, H.M.; Godfrey, K.M.; Cooper, C.; Robinson, S.M. Nausea and vomiting in early pregnancy: Effects on food intake and diet quality. Matern. Child Nutr. 2017, 13, e12389. [CrossRef] [PubMed]

26. Bärebring, L.; Mullally, D.; Glantz, A.; Elllis, J.; Hulthén, L.; Jagner, Å.; Bullarbo, M.; Winkvist, A.; Augustin, H. Sociodemographic factors associated with dietary supplement use in early pregnancy in a Swedish cohort. Br. J. Nutr. 2017, 119, 90-95.

27. Johansson, K.; A Hutcheon, J.; Stephansson, O.; Cnattingius, S. Pregnancy weight gain by gestational age and BMI in Sweden: A population-based cohort study. Am. J. Clin. Nutr. 2016, 103, 1278-1284. [CrossRef] [PubMed]

28. Gardner, R.M.; Lee, B.K.; Magnusson, C.; Rai, D.; Frisell, T.; Karlsson, H.; Idring, S.; Dalman, C. Maternal body mass index during early pregnancy, gestational weight gain, and risk of autism spectrum disorders: Results from a Swedish total population and discordant sibling study. Int. J. Epidemiol. 2015, 44, 870-883. [CrossRef] [PubMed]

29. Henriksson, P.; Eriksson, B.; Forsum, E.; Löf, M. Gestational weight gain according to Institute of Medicine recommendations in relation to infant size and body composition. Pediatr. Obes. 2015, 10, 388-394. [CrossRef]

30. Bärebring, L.; Amberntsson, A.; Winkvist, A.; Augustin, H. Validation of Dietary Vitamin D Intake from Two Food Frequency Questionnaires, Using Food Records and the Biomarker 25-Hydroxyvitamin D among Pregnant Women. Nutrients 2018, 10, 745. [CrossRef]

(C) 2020 by the authors. Licensee MDPI, Basel, Switzerland. This article is an open access article distributed under the terms and conditions of the Creative Commons Attribution (CC BY) license (http://creativecommons.org/licenses/by/4.0/). 